\title{
Vibralactone Biogenesis-Associated Analogues from Submerged Cultures of the Fungus Boreostereum vibrans
}

\author{
He-Ping Chen ${ }^{1} \cdot$ Meng-Yuan Jiang ${ }^{2} \cdot$ Zhen-Zhu Zhao $^{1} \cdot$ Tao Feng $^{1} \cdot$ Zheng-Hui Li $^{1} \cdot$ Ji-Kai Liu $^{1}$
}

Received: 22 October 2017 / Accepted: 23 November 2017 / Published online: 5 December 2017

(C) The Author(s) 2017. This article is an open access publication

\begin{abstract}
A scale-up fermentation of the fungus Boreostereum vibrans facilitated the isolation of six new vibralactone biogenesisassociated analogues, namely vibralactamide A (1), vibralactone $\mathrm{T}(\mathbf{2}), 13-O$-lactyl vibralactone (3), 10-O-acetyl vibralactone $\mathrm{G}(\mathbf{4}),(11 R, 12 R)$ - and $(11 S, 12 R)$-vibradiol $(\mathbf{5}, \mathbf{6})$. Their structures were established via extensive spectroscopic analyses, specific optical rotation comparison, and Snatzke's method. The biosynthetic pathway for vibralactamide A was postulated. The absolute configuration of vibralactone B was revised by single crystal X-ray diffraction analysis. This work puts the divergent vibralactone biosynthesis pathway one step further and expands the structural diversity of vibralactoneassociated compounds.
\end{abstract}

Graphical Abstract
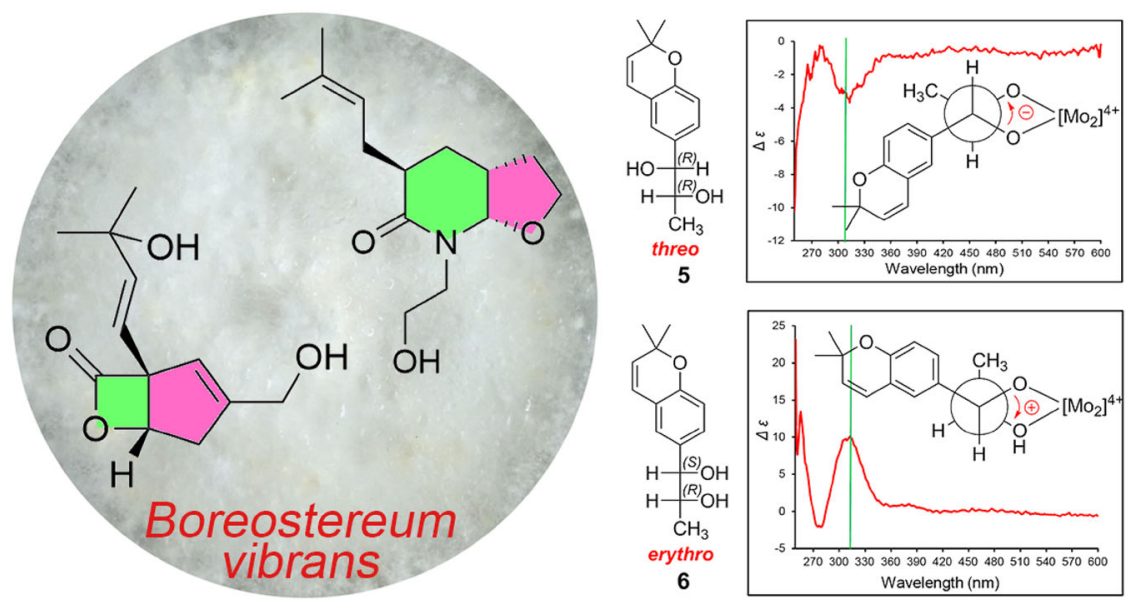

Electronic supplementary material The online version of this article (https://doi.org/10.1007/s13659-017-0147-5) contains supplementary material, which is available to authorized users.

Ji-Kai Liu

jkliu@mail.kib.ac.cn

1 School of Pharmaceutical Sciences, South-Central University for Nationalities, Wuhan 430074, People's Republic of China

2 Key Laboratory of Chemistry in Ethnic Medicinal Resources, State Ethnic Affairs Commission \& Ministry of Education, School of Ethnic Medicine, Yunnan Minzu University, Kunming 650504, People's Republic of China 
Keywords Basidiomycete · Boreostereum vibrans · Vibralactone $\cdot$ Structure revision · Snatzke's method

\section{Introduction}

Natural products from higher fungi origin are irreplaceable sources of architecturally distinct scaffolds for drug discovery [1,2]. The fungus Boreostereum vibrans is featured by producing a lipase inhibitor named vibralactone which harboring an unusual $\beta$-lactone group. In recent years, endeavors to explore the potential of producing diverse metabolites of B. vibrans by scale-up fermentation and/or changing culture medium compositions led to the isolation of plenty of bioactive vibralactone congeners and vibralactone biosynthetic-associated compounds [3-11], including vibralactoximes A-P which represented the first class of natural oxime esters [3]. The biosynthesis of vibralactone and divergent biosynthetic pathway for skeletally distinct vibralactone-associated compounds were illuminated [12, 13]. It was proved that all these compounds shared the biosynthetic precursor 3-prenyl-4-hydroxybenzylalcohol. An FAD-binding monooxygenase (VibMO1) from B. vibrans that converted prenyl 4-hydroxybenzoate into prenylhydroquinone was also characterized for the first time.

This study, as part of our ongoing interest in bioactive metabolites from higher fungi, focused on the trace compounds of scale-up submerged cultures of B. vibrans. As a result, six previously undescribed vibralactone biogenesisassociated analogues were identified. Herein, we report the isolation, structure elucidation, and absolute configuration determination via comparison of specific optical rotations and application of Snatzke's method of these new compounds (Fig. 1). We also make a revision of the absolute configuration of vibralactone $\mathrm{B}$.

\section{Results and Discussion}

Compound 1 was obtained as colorless oil. It had a molecular formula $\mathrm{C}_{14} \mathrm{H}_{23} \mathrm{O}_{3} \mathrm{~N}$ as deduced from the HREIMS molecular ion peak at $m / z 253.1672[\mathrm{M}]^{+}$(calcd for 253.1678, $\mathrm{C}_{14} \mathrm{H}_{23} \mathrm{O}_{3} \mathrm{~N}$ ), indicating four degrees of hydrogen deficiency. The IR spectrum absorption bands at 3447 and $1637 \mathrm{~cm}^{-1}$ indicated the presence of hydroxy and carbonyl groups, respectively. The 1D NMR spectroscopic data (Tables 1 and 2) displayed fourteen carbon signals ascribable to two methyl singlets, six methylenes (two oxygenated), four methines (one olefinic, one oxygenated), and two quaternary carbons. The presence of a carbonyl $\left(\delta_{\mathrm{C}} 173.8, \mathrm{C}-7\right)$ and a double bond $\left(\delta_{\mathrm{C}} 123.2, \mathrm{C}-9\right.$; 133.5, C-10) accounting for two degrees of unsaturation suggesting two cycles in $\mathbf{1}$. Further elucidating the 2D
NMR spectra allowed the completion of planar structure of 1. The HMBC correlations (Fig. 2) from the two methyl singlets $\left(\delta_{\mathrm{H}} 1.60,1.68\right)$ to $\mathrm{C}-9$ and $\mathrm{C}-10$, along with the ${ }^{1} \mathrm{H}-{ }^{1} \mathrm{H}$ COSY correlations between $\mathrm{H}-8\left(\delta_{\mathrm{H}} 2.50,2.13\right)$ and H-9 $\left(\delta_{\mathrm{H}}\right.$ 5.14) suggested the existence of an isopentenyl group. Analysis of the ${ }^{1} \mathrm{H}-{ }^{1} \mathrm{H}$ COSY spectrum allowed the following sequential connectivity from $\mathrm{C}-8$ to $\mathrm{C}-5$, from C-3 to C-13 (Fig. 2). The HMBC correlations from $\mathrm{H}-8$ to C-1 $\left(\delta_{\mathrm{C}} 38.3\right), \mathrm{C}-2\left(\delta_{\mathrm{C}} 28.9\right)$, and C-7 revealed that the carbonyl group connected to $\mathrm{C}-1$. The key HMBC correlations from $\mathrm{H}-13\left(\delta_{\mathrm{H}} 5.17\right)$ to the typical oxygenated methylene C-5 $\left(\delta_{\mathrm{C}} 65.7\right)$ and carbonyl C-7 as well as the chemical shift of C-13 $\left(\delta_{\mathrm{C}} 91.6\right)$ [14] led to the assignments of an ether bond between $\mathrm{C}-5 / \mathrm{C}-13$, and a nitrogen atom between $\mathrm{C}-7 / \mathrm{C}-13$, which constructed a hexahydrofuro[2,3- $b]$ pyridin-6(2H)-one scaffold. The remaining two carbons $\left(\mathrm{C}-1^{\prime}, \delta_{\mathrm{C}} 49.7 ; \mathrm{C}-2^{\prime}, 61.5\right)$ was assigned to a $2^{\prime}$ hydroxyethyl substituted at the nitrogen atom as supported by the ${ }^{1} \mathrm{H}-{ }^{1} \mathrm{H}$ COSY correlations between $\mathrm{H}-1^{\prime}\left(\delta_{\mathrm{H}} 3.61\right.$, 3.38) and $\mathrm{H}-2^{\prime}\left(\delta_{\mathrm{H}} 3.61\right)$, and HMBC correlations from $\mathrm{H}-1^{\prime}$ to $\mathrm{C}-7$ and $\mathrm{C}-13$. When changing NMR solvents from acetone- $d_{6}$ to DMSO- $d_{6}$, the resultant $2^{\prime}-\mathrm{OH}$ proton signal at $\delta_{\mathrm{H}} 4.66(\mathrm{t}, J=5.6 \mathrm{~Hz})$ and less overlapped signals reinforced the above assignments.

The relative configuration of compound 1 was established by interpretation of the ROESY spectrum. Evident ROESY signals between $\mathrm{H}-3\left(\delta_{\mathrm{H}} 2.71\right) / \mathrm{H}-13, \mathrm{H}-1\left(\delta_{\mathrm{H}}\right.$ $2.34) / \mathrm{H}-4 \alpha \quad\left(\delta_{\mathrm{H}} 1.82\right), \mathrm{H}-8 \mathrm{a} \quad\left(\delta_{\mathrm{H}} 2.13\right) / \mathrm{H}-2 \beta\left(\delta_{\mathrm{H}} 1.81\right)$ indicated that the two rings were cis-fused and the isopentenyl group was $\beta$-oriented (Fig. 3). Therefore, compound 1 was established as shown in Fig. 1 and was trivially named as vibralactamide A.

The biosynthetic pathway of vibralactamide A (1) was proposed as shown in Scheme 1. It was supposed that 3-prenyl-4-hydroxybenzylalcohol (A) underwent a $\mathrm{C}-\mathrm{C}$ cleavage reaction to give 1,5-seco-vibralactone $(\mathbf{B})$. The intermediate $\mathbf{B}$ was then subjected to cascade reduction and oxidation reactions to give $\mathbf{C}$. The key intermediate D which formed by nucleophilic addition of $\mathbf{C}$ with 2-aminoethanol was subjected to hydroxylation/nucleophilic addition/dihydroxylation processes to afford compound 1.

Compound 2 was obtained as colorless oil. The molecular formula was established as $\mathrm{C}_{12} \mathrm{H}_{16} \mathrm{O}_{4}$ by the sodium adduct ion peak at $\mathrm{m} / \mathrm{z} 247.0937[\mathrm{M}+\mathrm{Na}]^{+}$(calcd for 247.0941, $\mathrm{C}_{12} \mathrm{H}_{16} \mathrm{O}_{4} \mathrm{Na}$ ) in HRESIMS analysis. The 1D NMR spectra of compound 2 displayed signals of two overlapped methyl singlets, two methylenes, four methines (three olefinic, one was oxygenated), and four quaternary carbons (one carbonyl, one olefinic) (Tables 1 and 2). All 


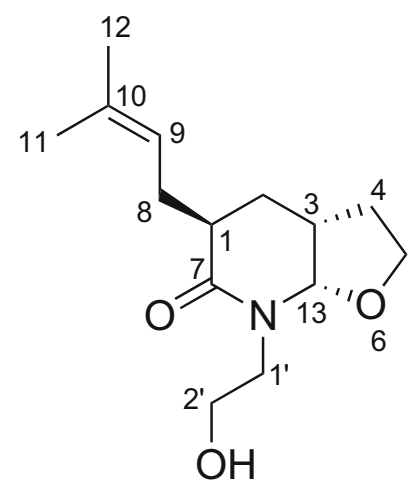

1

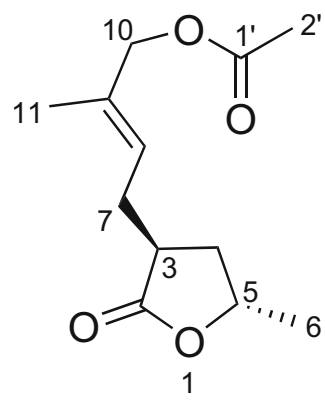

4

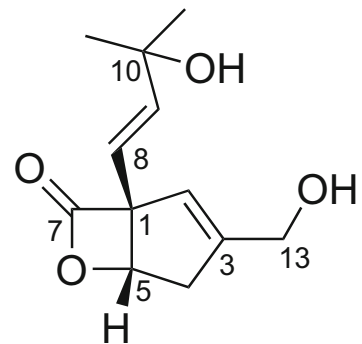

2

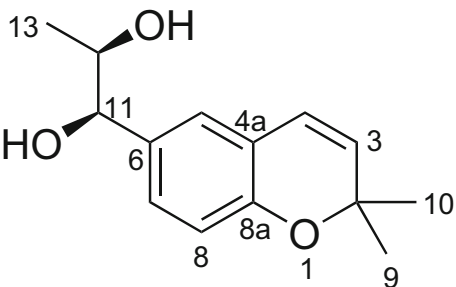

5<smiles>CC(C)=CC[C@]12C=C(COC(=O)C(C)O)C[C@H]1OC2=O</smiles>

3<smiles>C[C@H](O)[C@H](O)c1ccc2c(c1)C=CC(C)(C)O2</smiles>

6
Fig. 1 Chemical structures of compounds 1-6

these data exhibit similarities to those of vibralactone [8]. However, the presence of two trans-double bond protons $\left(\delta_{\mathrm{H}} 5.88, J=16.0 \mathrm{~Hz}, \mathrm{H}-8 ; \delta_{\mathrm{H}} 5.99, J=16.0 \mathrm{~Hz}, \mathrm{H}-9\right)$, and the HMBC correlations from H-9 to Me-11/Me-12 $\left(\delta_{\mathrm{C}}\right.$ $30.1), \mathrm{C}-10\left(\delta_{\mathrm{C}} 76.4\right)$, and from $\mathrm{H}-8$ to $\mathrm{C}-1\left(\delta_{\mathrm{C}} 70.2\right), \mathrm{C}-7$ $\left(\delta_{\mathrm{C}} 172.5\right)$, and $\mathrm{C}-2\left(\delta_{\mathrm{C}} 121.2\right)$ suggested that the $\mathrm{C} 9-\mathrm{C} 10$ double bond in vibralactone shifted to the position $\mathrm{C} 8-\mathrm{C} 9$, while C-10 was substituted by a hydroxy in 2 (Fig. 2). This assignment was consistent with the HRESIMS result. The relative configuration of compound $\mathbf{2}$ was determined as $1 R^{*}, 5 S^{*}$ via ROESY correlations between $\mathrm{H}-5\left(\delta_{\mathrm{H}} 4.99\right)$ and $\mathrm{H}-8\left(\delta_{\mathrm{H}} 5.88\right)$ (Fig. 3$)$, and the absolute configuration was assigned as $1 R, 5 \mathrm{~S}$ by comparison of the specific optical rotation value with those of vibralactone $\left([\alpha]_{\mathrm{D}}^{25}-61.3\right.$ for $\mathbf{2}$, $[\alpha]_{\mathrm{D}}^{26}-135.1$ for vibralactone). Thus, compound 2 was elucidated as shown in Fig. 1, and was given the trivial name vibralactone $\mathrm{T}$.

The ${ }^{13} \mathrm{C}$ NMR and DEPT spectra (Tables 1 and 2) of the colorless oil compound $\mathbf{3}$ exhibited signals ascribable to three methyls, three methylenes, four methines, and five quaternary carbons (two carbonyls). These data show high resemblance to those of vibralactone [8]. Compared to vibralactone, the additional three carbons at $\delta_{\mathrm{C}} 176.0$ (C$\left.1^{\prime}\right), 68.0\left(\mathrm{C}-2^{\prime}\right), 20.8\left(\mathrm{C}-3^{\prime}\right)$ and corresponding protons at $\delta_{\mathrm{H}} 1.39\left(\mathrm{~d}, J=6.9 \mathrm{~Hz}, \mathrm{H}-3^{\prime}\right), 4.31\left(\mathrm{q}, J=6.9 \mathrm{~Hz}, \mathrm{H}-2^{\prime}\right)$ as well as the $\mathrm{HMBC}$ correlations from $\mathrm{H}-3^{\prime}$ to $\mathrm{C}-2^{\prime}$ and $\mathrm{C}-3^{\prime}$ indicated the presence of a lactyl moiety in $\mathbf{3}$. The lactyl moiety attached at the oxygen atom at $\mathrm{C}-13$ by the key HMBC correlation from $\mathrm{H}-13\left(\delta_{\mathrm{H}} 4.74,4.79\right)$ to $\mathrm{C}-1^{\prime}$. This assignment agreed with the HRESIMS result which gave a sodium adduct ion peak at $m / z 303.1206[\mathrm{M}+\mathrm{Na}]^{+}$ (calcd for 303.1203, $\mathrm{C}_{15} \mathrm{H}_{20} \mathrm{O}_{5} \mathrm{Na}$ ). The absolute configuration of the vibralactone part was determined as $1 R, 5 S$ via biogenetic consideration and evident ROESY correlations between $\mathrm{H}-5 / \mathrm{H}-8$. However, attempt to settle the absolute configuration of chiral center $\mathrm{C}-2^{\prime}$ of the lactyl moiety by Mosher's method failed. With $(R)$-MTPA derivative of $\mathbf{3}$ in hand, while the counterpart (S)-MTPA derivative was missing because of the insufficient quantity of compound $\mathbf{3}$. Therefore, compound 3 was identified as 13-O-lactyl-vibralactone (Fig. 1).

Compound 4 was isolated as colorless oil. The 1D NMR data (Tables 1 and 2) displayed high similarities to those of vibralactone G [9], a $\gamma$-lactone derivative obtained from the same fungus but from different batches of cultures. Analysis of the 2D NMR spectra suggested that the 10-OH of vibralactone $\mathrm{G}$ was acetylated to give compound $\mathbf{4}$, which supported by the HMBC correlation from $\mathrm{H}-10\left(\delta_{\mathrm{H}} 4.43\right)$ and $\mathrm{H}-2^{\prime}\left(\delta_{\mathrm{H}} 2.01\right)$ to the carbonyl $\mathrm{C}-1^{\prime}\left(\delta_{\mathrm{C}} 170.8\right)$. The relative configuration of compound 4 was proved to be 
Table $1{ }^{1} \mathrm{H}$ NMR spectroscopic data for compounds $\mathbf{1 - 6}(600 \mathrm{MHz})$

\begin{tabular}{|c|c|c|c|c|c|c|c|}
\hline No. & $\mathbf{1}^{\mathrm{a}}$ & $\mathbf{1}^{\mathrm{b}}$ & $2^{\mathrm{a}}$ & $3^{\mathrm{c}}$ & $4^{\mathrm{a}}$ & $5^{\mathrm{c}}$ & $6^{\mathrm{a}}$ \\
\hline 1 & $2.34, \mathrm{~m}$ & $2.30, \mathrm{~m}$ & & & & & \\
\hline 2 & $\begin{array}{l}\text { 1.65, ddd (13.6, } \\
11.0,5.4) \\
1.81, \text { ddd }(13.6,4.6 \text {, } \\
4.3)\end{array}$ & $\begin{array}{l}1.56, \text { ddd }(13.6, \\
10.7,5.3) \\
1.70, \text { overlapped }\end{array}$ & $5.64, \mathrm{~s}$ & $5.68, \mathrm{~s}$ & & & \\
\hline 3 & $2.71, \mathrm{~m}$ & $2.61, \mathrm{~m}$ & & & $\begin{array}{l}2.79, \text { ddd }(16.8, \\
7.7,5.0)\end{array}$ & $5.68, \mathrm{~d}(9.8)$ & $5.70, \mathrm{~d}(9.8)$ \\
\hline 4 & $\begin{array}{l}2.14, \mathrm{~m} \\
1.82, \mathrm{~m}\end{array}$ & $\begin{array}{l}2.08, \mathrm{~m} \\
1.73, \mathrm{~m}\end{array}$ & $\begin{array}{l}2.66, \mathrm{~d}(18.7) \\
2.87, \mathrm{dd} \\
\quad(18.7,5.7)\end{array}$ & $\begin{array}{l}2.72, \mathrm{~d}(19.0) \\
2.83, \mathrm{dd} \\
\quad(19.0,6.0)\end{array}$ & $\begin{array}{l}\text { 2.12, ddd (12.8, } \\
7.7,7.7) \\
\text { 2.04, overlapped }\end{array}$ & $6.36, \mathrm{~d}(9.8)$ & $6.38, \mathrm{~d}(9.8)$ \\
\hline 5 & $\begin{array}{l}3.84 \text {, dd }(13.8,13.8, \\
5.8) \\
3.69, \text { br. dd }(13.8, \\
7.8)\end{array}$ & $\begin{array}{l}3.74 \text {, ddd }(8.2,8.1 \text {, } \\
6.1) \\
3.64 \text {, ddd }(8.2,8.1 \text {, } \\
6.5)\end{array}$ & $4.99, \mathrm{~d}(5.7)$ & $4.89, \mathrm{~d}(6.0)$ & $4.65, \mathrm{~m}$ & $6.99, \mathrm{~d}(2.1)$ & $7.04, \mathrm{~d}(2.0)$ \\
\hline 6 & & & & & $1.32, \mathrm{~d}(6.4), 3 \mathrm{H}$ & & \\
\hline 7 & & & & & $\begin{array}{l}2.46, \mathrm{~m} \\
2.31, \mathrm{~m}\end{array}$ & $\begin{array}{l}\text { 7.07, dd (8.3, } \\
2.1)\end{array}$ & $\begin{array}{l}\text { 7.10, dd (8.2, } \\
2.0)\end{array}$ \\
\hline 8 & $\begin{array}{l}\text { 2.50, br. ddd (14.3, } \\
5.3,5.3) \\
2.13 \text {, overlapped }\end{array}$ & $\begin{array}{l}2.41, \mathrm{~m} \\
2.05, \text { overlapped }\end{array}$ & $5.88, \mathrm{~d}(16.0)$ & $\begin{array}{l}2.43, \mathrm{dd} \\
(15.0,7.5) \\
2.61, \mathrm{dd} \\
(15.0,7.5)\end{array}$ & $5.50, \mathrm{t}(7.5)$ & $6.68, \mathrm{~d}(8.3)$ & $6.66, \mathrm{~d}(8.2)$ \\
\hline 9 & 5.14 , br. t (7.3) & $5.10, \mathrm{t}(7.3)$ & $5.99, \mathrm{~d}(16.0)$ & $5.17, \mathrm{t}(7.5)$ & & $1.39, \mathrm{~s}, 3 \mathrm{H}$ & $1.38, \mathrm{~s}, 3 \mathrm{H}$ \\
\hline 10 & & & & & $4.43, \mathrm{~s}, 2 \mathrm{H}$ & $1.39, \mathrm{~s}, 3 \mathrm{H}$ & $1.38, \mathrm{~s}, 3 \mathrm{H}$ \\
\hline 11 & $1.60, \mathrm{~s}, 3 \mathrm{H}$ & $1.59, \mathrm{~s}, 3 \mathrm{H}$ & $1.26, \mathrm{~s}, 3 \mathrm{H}$ & $1.66, \mathrm{~s}, 3 \mathrm{H}$ & $1.68, \mathrm{~s}, 3 \mathrm{H}$ & $4.24, \mathrm{~d}(7.2)$ & $4.44, \mathrm{~d}(4.0)$ \\
\hline 12 & $1.68, \mathrm{~s}, 3 \mathrm{H}$ & $1.68, \mathrm{~s}, 3 \mathrm{H}$ & $1.26, \mathrm{~s}, 3 \mathrm{H}$ & $1.73, \mathrm{~s}, 3 \mathrm{H}$ & & $3.77, \mathrm{~m}$ & $3.82, \mathrm{~m}$ \\
\hline 13 & $5.17, \mathrm{~d}(7.0)$ & $5.15, \mathrm{~d}(7.0)$ & $\begin{array}{l}4.17, \mathrm{dd} \\
(15.6,6.8) \\
4.20, \mathrm{dd} \\
(15.6,6.8)\end{array}$ & $\begin{array}{l}4.74, \mathrm{~d}(13.0) \\
4.79, \mathrm{~d}(13.0)\end{array}$ & & $\begin{array}{l}0.96, \mathrm{~d}(6.4), \\
3 \mathrm{H}\end{array}$ & $\begin{array}{l}1.04, \mathrm{~d}(6.3), \\
3 \mathrm{H}\end{array}$ \\
\hline $1^{\prime}$ & $\begin{array}{l}\text { 3.61, overlapped } \\
3.38, \mathrm{~m}\end{array}$ & $\begin{array}{l}3.31 \text {, dd }(13.8,6.6 \text {, } \\
6.6) \\
3.41 \text {, overlapped }\end{array}$ & & & & & \\
\hline $2^{\prime}$ & 3.61 , overlapped, $2 \mathrm{H}$ & $\begin{array}{l}3.46 \text {, overlapped, } \\
2 \mathrm{H}\end{array}$ & & $4.31, \mathrm{q}(6.9)$ & $2.01, \mathrm{~s}, 3 \mathrm{H}$ & & \\
\hline $3^{\prime}$ & & & & $\begin{array}{l}1.39, \mathrm{~d}(6.9), \\
3 \mathrm{H}\end{array}$ & & & \\
\hline $2^{\prime}-\mathrm{OH}$ & 3.84 , overlapped & $4.66, \mathrm{t}(5.6)$ & & & & & \\
\hline $11-\mathrm{OH}$ & & & & & & & 4.12 , br. s \\
\hline $12-\mathrm{OH}$ & & & & & & & 3.54 , br. s \\
\hline $13-\mathrm{OH}$ & & & $4.22, \mathrm{t}(6.8)$ & & & & \\
\hline
\end{tabular}

${ }^{\mathrm{a}}$ Recorded in acetone- $d_{6}$

${ }^{\mathrm{b}}$ Recorded in DMSO- $d_{6}$

${ }^{c}$ Recorded in $\mathrm{CD}_{3} \mathrm{OD}$

same with that of vibralactone $\mathrm{G}$ according to the ROESY correlations between $\mathrm{H}-3\left(\delta_{\mathrm{H}} 2.79\right)$ and Me-6 $\left(\delta_{\mathrm{H}} 1.32\right)$. Thus, compound 4 was identified as 10 - $O$-acetyl vibralactone $\mathrm{G}$ (Fig. 1).

Compounds 5 and $\mathbf{6}$ were purified as white powder. HREIMS analyses suggested that these two compounds had the same molecular formula of $\mathrm{C}_{14} \mathrm{H}_{18} \mathrm{O}_{3}$. The close NMR data (Tables 1 and 2) of these two compounds which showed resemblance to those of vibranether revealed that compounds 5 and $\mathbf{6}$ possessed same planar structure and were analogues of vibranether [10]. The absence of the methoxy signal in ${ }^{1} \mathrm{H}$ NMR spectra of compounds 5 and 6 
Table $2{ }^{13} \mathrm{C}$ NMR

Spectroscopic Data for

Compounds 1-6 (150 MHz)

\begin{tabular}{|c|c|c|c|c|c|c|c|}
\hline No. & $\mathbf{1}^{\mathrm{a}}$ & $1^{\mathrm{b}}$ & $2^{\mathrm{a}}$ & $3^{\mathrm{c}}$ & $4^{a}$ & $5^{c}$ & $6^{\mathrm{a}}$ \\
\hline 1 & $38.3, \mathrm{CH}$ & 36.9 & $70.2, \mathrm{C}$ & $76.8, \mathrm{C}$ & & & \\
\hline 2 & $28.9, \mathrm{CH}_{2}$ & 27.7 & $121.2, \mathrm{CH}$ & $126.4, \mathrm{CH}$ & 178.7, C & $77.3, \mathrm{C}$ & 76.6, C \\
\hline 3 & $35.0, \mathrm{CH}$ & 33.7 & $149.5, \mathrm{C}$ & $143.3, \mathrm{C}$ & $39.7, \mathrm{CH}$ & $132.1, \mathrm{CH}$ & $131.5, \mathrm{CH}$ \\
\hline 4 & $30.8, \mathrm{CH}_{2}$ & 29.6 & $37.8, \mathrm{CH}_{2}$ & $38.7, \mathrm{CH}_{2}$ & $34.8, \mathrm{CH}_{2}$ & $123.4, \mathrm{CH}$ & $123.2, \mathrm{CH}$ \\
\hline $4 a$ & & & & & & $122.4, \mathrm{C}$ & $122.4, \mathrm{C}$ \\
\hline 5 & $65.7, \mathrm{CH}_{2}$ & 64.7 & $81.2, \mathrm{CH}$ & $80.0, \mathrm{CH}$ & $75.4, \mathrm{CH}$ & $126.2, \mathrm{CH}$ & $125.7, \mathrm{CH}$ \\
\hline 6 & & & & & $21.3, \mathrm{CH}_{3}$ & 135.6, C & $135.9, \mathrm{C}$ \\
\hline 7 & $173.8, \mathrm{C}$ & 172.2 & $172.5, \mathrm{C}$ & 174.6, C & 29.0, $\mathrm{CH}_{2}$ & $128.9, \mathrm{CH}$ & $128.3, \mathrm{CH}$ \\
\hline 8 & $29.8, \mathrm{CH}_{2}$ & 28.9 & $119.4, \mathrm{CH}$ & $28.5, \mathrm{CH}_{2}$ & 125.6, CH & $116.9, \mathrm{CH}$ & $116.1, \mathrm{CH}$ \\
\hline $8 \mathrm{a}$ & & & & & & 153.8, C & $152.8, \mathrm{C}$ \\
\hline 9 & $123.2, \mathrm{CH}$ & 122.2 & $143.2, \mathrm{CH}$ & $118.8, \mathrm{CH}$ & $133.9, \mathrm{C}$ & $28.1, \mathrm{CH}_{3}$ & 28.1, $\mathrm{CH}_{3}$ \\
\hline 10 & $133.5, \mathrm{C}$ & 132.5 & $76.4, \mathrm{C}$ & 137.2, C & $69.8, \mathrm{CH}_{2}$ & $28.2, \mathrm{CH}_{3}$ & $28.1, \mathrm{CH}_{3}$ \\
\hline 11 & $17.9, \mathrm{CH}_{3}$ & 17.8 & $30.2, \mathrm{CH}_{3}$ & $18.2, \mathrm{CH}_{3}$ & $14.1, \mathrm{CH}_{3}$ & 79.9, CH & 77.9, $\mathrm{CH}$ \\
\hline 12 & $26.0, \mathrm{CH}_{3}$ & 25.7 & $30.2, \mathrm{CH}_{3}$ & $26.1, \mathrm{CH}_{3}$ & & $72.8, \mathrm{CH}$ & 71.9, $\mathrm{CH}$ \\
\hline 13 & $91.6, \mathrm{CH}$ & 90.0 & $61.1, \mathrm{CH}_{2}$ & $63.5, \mathrm{CH}_{2}$ & & $19.2, \mathrm{CH}_{3}$ & $18.2, \mathrm{CH}_{3}$ \\
\hline $1^{\prime}$ & 49.7, $\mathrm{CH}_{2}$ & 47.3 & & 176.0, C & $170.8, \mathrm{C}$ & & \\
\hline $2^{\prime}$ & $61.5, \mathrm{CH}_{2}$ & 58.7 & & $68.0, \mathrm{CH}$ & $20.8, \mathrm{CH}_{3}$ & & \\
\hline $3^{\prime}$ & & & & $20.8, \mathrm{CH}_{3}$ & & & \\
\hline
\end{tabular}

${ }^{a}$ Recorded in acetone- $d_{6}$

${ }^{\mathrm{b}}$ Recorded in DMSO- $d_{6}$

${ }^{\mathrm{c}}$ Recorded in $\mathrm{CD}_{3} \mathrm{OD}$

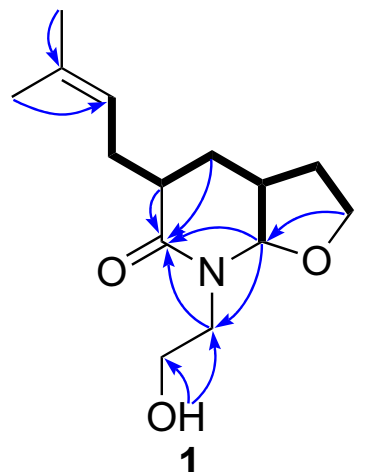

1

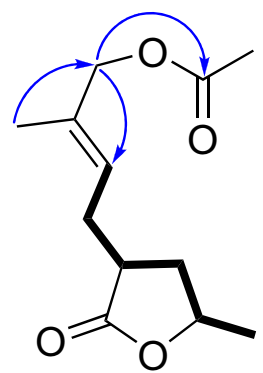

4

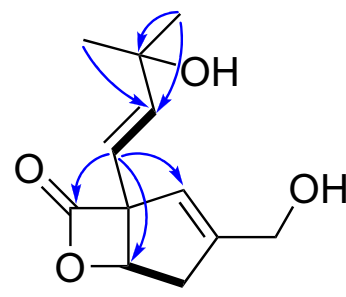

2

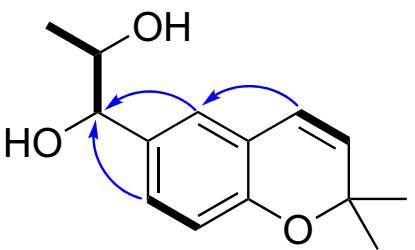

$5 / 6$

Fig. 2 Selected ${ }^{1} \mathrm{H}-{ }^{1} \mathrm{H}$ COSY and HMBC correlations of compounds 1-6 


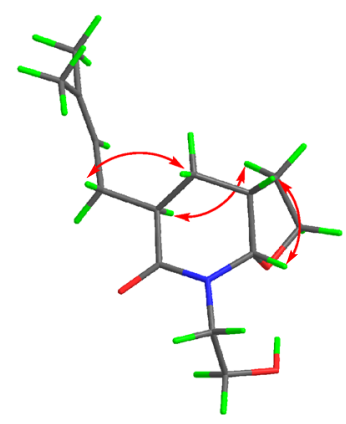

1

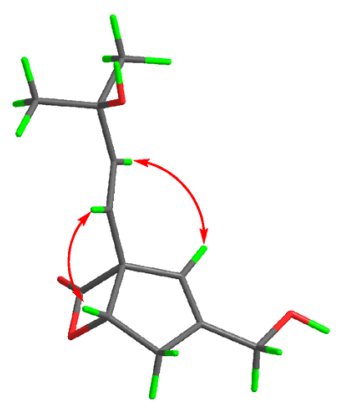

2

\section{$\sim$ ROESY}

Fig. 3 Selected ROESY correlations of compounds $\mathbf{1}$ and $\mathbf{2}$

compared to that of vibranether enabled the establishment of planar structure of these two compounds as chromene vicinal diol derivatives (Fig. 1). The remarkable differences of chemical shifts at the position C-11, C-12, and $\mathrm{C}-13$ though recorded in different NMR solvents suggested that these two compounds were C-11/C-12 diastereomers. Compounds 5 and $\mathbf{6}$ were determined as threo and erythro configurations by the coupling constants between $\mathrm{H}-11$ and $\mathrm{H}-12(J=4.0 \mathrm{~Hz}$ for $5 ; J=7.2 \mathrm{~Hz}$ for $\mathbf{6})$ as well as the chemical shifts of 13-methyls [15, 16]. The absolute configuration of the 11,12-diol moieties of compounds 5 and $\mathbf{6}$ were assigned using the in situ dimolybdenum CD method developed by Snatzke and Frelek [17, 18]. When adding dimolybdenum tetraacetate $\left[\mathrm{Mo}_{2}(\mathrm{OAc})_{4}\right]$ to solution of $\mathbf{5}$ and $\mathbf{6}$ in DMSO, respectively, metal complexes were generated as an auxiliary chromophore. The Cottonogenic diol derivatives are constrained into a chiral, gauche arrangement with the bulkier substituents adopt a pseudoequatorial position pointing away from the remaining portion of the complex. The signs of band II $(310 \mathrm{~nm})$ are same with the $\mathrm{O}-\mathrm{C}-\mathrm{C}-\mathrm{O}$ dihedral angle, and are most safely related to the absolute configuration of the diol. As shown in Fig. 4, the positive and negative Cotton effects at $310 \mathrm{~nm}$ of compounds 5 and $\mathbf{6}$ metal complexes corresponding to the clockwise and counter-clockwise of the $\mathrm{O}-$ $\mathrm{C}-\mathrm{C}-\mathrm{O}$ dihedral angles, respectively, which led to the unambiguously assign of the absolute configurations of $\mathbf{5}$ and $\mathbf{6}$ as $11 R, 12 R$ and $11 S, 12 R$, respectively [19, 20]. Therefore, compounds $\mathbf{5}$ and $\mathbf{6}$ were elucidated as shown in Fig. 1 and were given the respective names $(11 R, 12 R)$ - and $(11 S, 12 R)$-vibradiol.

The previously described compound vibralactone B (7) possessing an epoxy ring at $\mathrm{C} 2-\mathrm{C} 3$ was re-encountered in this research with a yield of more than $3 \mathrm{~g}$ [6]. Re-examined of the ROESY spectrum suggested that the mis-assignment of configuration of the epoxy ring as supported by the obvious ROESY correlations between $\mathrm{H}-8 / \mathrm{H}-2$, and H-2/H-13 (Fig. 5), suggestive of $\alpha$ configuration instead of $\beta$ configuration of the epoxy ring. Finally, crystals of 7 suitable for single crystal X-ray diffraction analysis were cultured via slowly evaporated methanol. As shown in Fig. 5, the X-ray diffraction result unequivocally determined the epoxy ring as $\alpha$ configuration.

In conclusion, six previously undescribed compounds were isolated from the scale-up fermentation of the fungus B. vibrans. All these compounds are biosynthetically related. Vibralactamide A (1) represents the other type of nitrogen-containing vibralactone derivative possible originated from different nitrogen atom-introducing pathway comparing with those of vibralactoximes A-P. This work provided further evidences for divergent vibralactone biosynthesis pathway and expanded the structural diversity of vibralactone-related compounds.

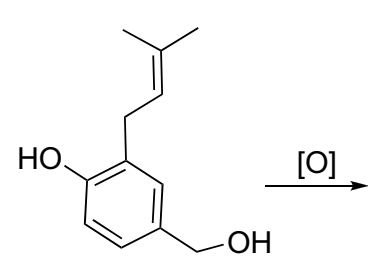

A

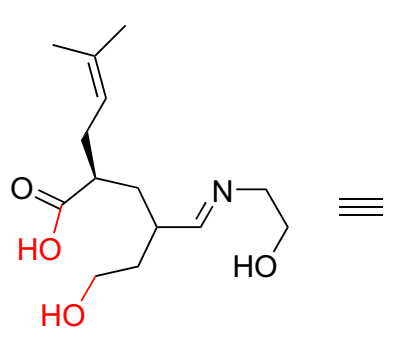

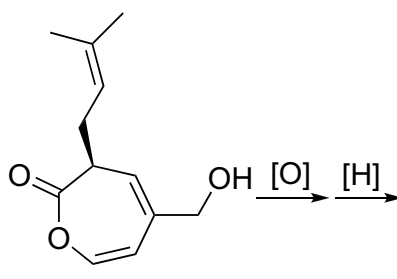

B

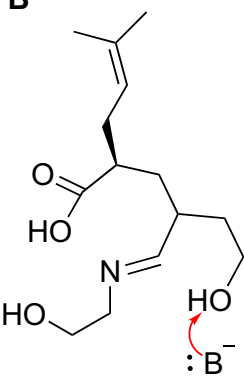

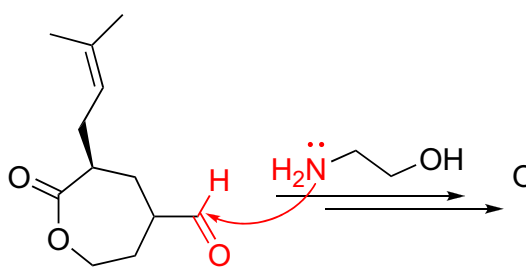

C

$\mathrm{HB}$

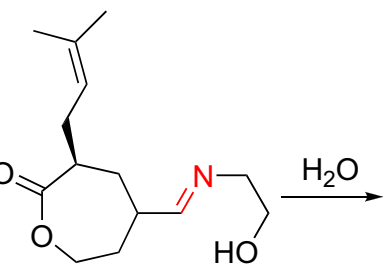

D<smiles>CC(C)=CC[C@@H]1C[C@@H]2CCO[C@H]2N(CCO)C1=O</smiles>

Scheme 1 Proposed biosynthetic pathway for compound 1 
<smiles>C#CCCCC(C)C(O)C(O)c1ccc2c(c1)C=CC(C)(C)O2</smiles>

5<smiles></smiles>

$5 a$<smiles>CC1C2CC3CC1C(O)(O)C(C2)C3c1ccc2c(c1)C=CC(C)(C)O2</smiles>

$5 b$<smiles>CC1C(c2ccc3c(c2)C=CC(C)(C)O3)CC2C(O)C3CC1C2C3O</smiles>

5c

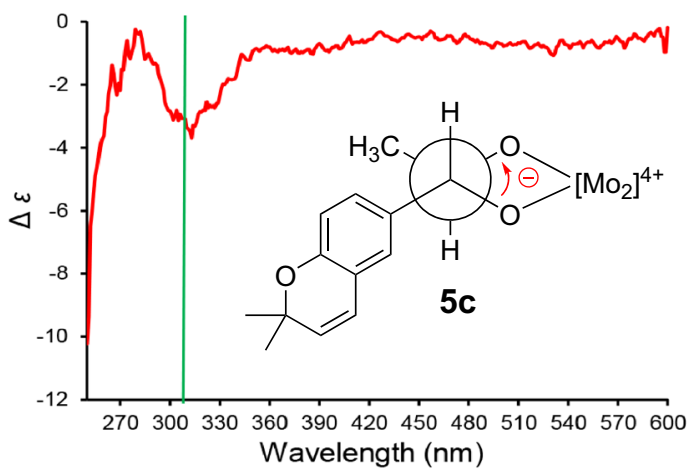<smiles>C#CC(O)C(O)C(C)c1ccc2c(c1)C=CC(C)(C)O2</smiles>

6<smiles>CC1C2CC3C(O)C(CCC13c1ccc3c(c1)C=CC(C)(C)O3)C2O</smiles>

$6 a$<smiles>CC1C2CC3(O)C(c4ccc5c(c4)C=CC(C)(C)O5)C1C3C2O</smiles>

$6 b$<smiles></smiles>

6c

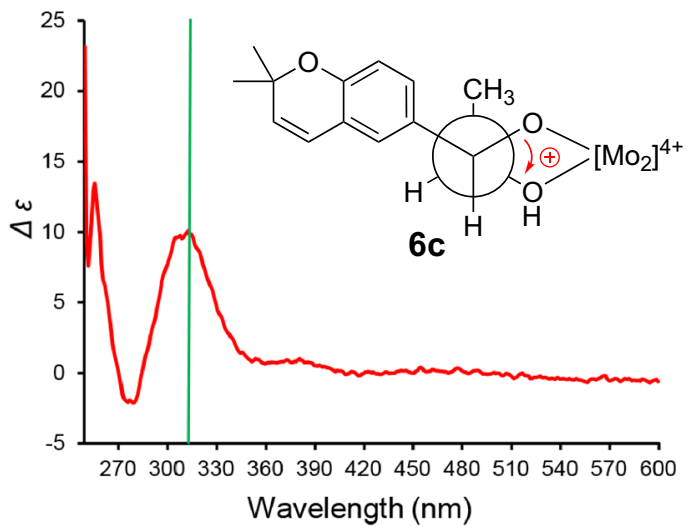

Fig. 4 Fischer projections of compounds $\mathbf{5}$ and $\mathbf{6}$; Newman projections of the possible conformers $5 \mathbf{a}, 5 \mathbf{b}, \mathbf{5} \mathbf{c}$ for $\mathbf{5}$, and $\mathbf{6 a}, \mathbf{6 b}, \mathbf{6 c}$ for $\mathbf{6}$; and CD spectra of in situ formed Mo-complexes of $\mathbf{5}$ and $\mathbf{6}$ in DMSO after $0.5 \mathrm{~h}$ from dissolving in the 1:1.2 ligand-to-metal ratio (green lines marked the position of $310 \mathrm{~nm}$ ) (a)

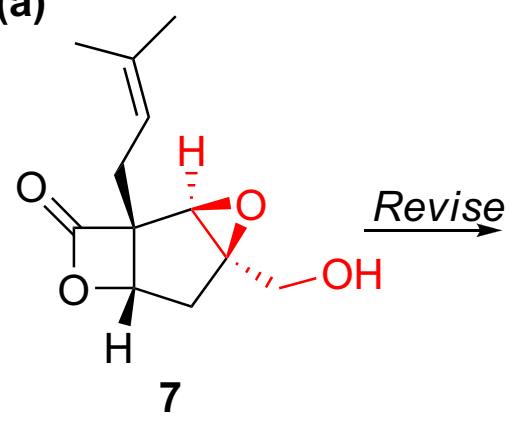

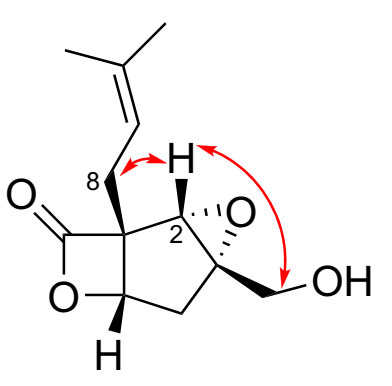

んROESY (b)

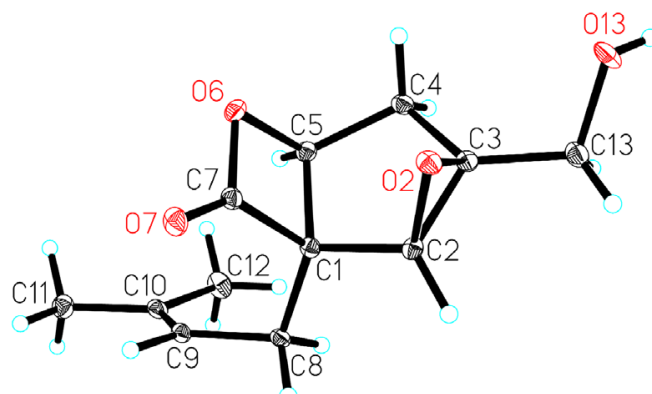

Fig. 5 a Structure revision of vibralactone B (7); b ORTEP drawing of compound 7

\section{Experimental Section}

\subsection{General Experimental Procedures}

Optical rotations were obtained on a JASCO P-1020 digital polarimeter (Horiba, Kyoto, Japan). UV spectra were recorded on a Shimadzu UV-2401PC UV-visible recording spectrophotometer (Shimadzu, Kyoto, Japan). 1D and 2D NMR spectra were obtained on a Bruker Avance III $600 \mathrm{MHz}$ spectrometer (Bruker Corporation, Karlsruhe, Germany). HRESIMS were recorded on an Agilent 6200
Q-TOF MS system (Agilent Technologies, Santa Clara, CA, USA). HREIMS were obtained on a Waters Autospec Premier P776 mass spectrometer. Single crystal X-ray diffraction was performed on an APEX II DUO spectrophotometer (Bruker AXS GmbH, Karlsruhe, Germany). Sephadex LH-20 (Amersham Biosciences, Uppsala, Sweden) and silica gel (Qingdao Haiyang Chemical Co., Ltd) were used for column chromatography (CC). Medium pressure liquid chromatography (MPLC) was performed on a Büchi Sepacore System equipped with pump manager C-615, pump modules C-605 and fraction collector C-660 
(Büchi Labortechnik AG, Flawil, Switzerland), and columns packed with Chromatorex C-18 (40-75 $\mu \mathrm{m}$, Fuji Silysia Chemical Ltd., Kasugai, Japan). Preparative high performance liquid chromatography (prep-HPLC) were performed on an Agilent 1260 liquid chromatography system equipped with Zorbax SB-C18 column (particle size $5 \mu \mathrm{m}$, dimension $9.4 \mathrm{~mm} \times 150 \mathrm{~mm}$, flow rate $8 \mathrm{~mL} /$ min, respectively) and a DAD detector (Agilent Technologies, Santa Clara, CA, USA).

\subsection{Fungal Material and Cultivation}

The fungus $B$. vibrans was collected from the Ailao Mountains of Yunnan Province, P. R. China in August 2005, and identified by Prof. Mu Zang (Kunming Institute of Botany, CAS), who is a mushroom specialist. A voucher specimen of B. vibrans was deposited in the Herbarium of KIB. The culture medium to ferment this fungus consist of $5 \%$ glucose, $0.15 \%$ peptone from porcine meat, $0.5 \%$ yeast extract, $0.05 \% \mathrm{KH}_{2} \mathrm{PO}_{4}$, and $0.05 \% \mathrm{MgSO}_{4}$. Five hundred 500-mL Erlenmeyer flasks each containing $350 \mathrm{~mL}$ of culture medium were inoculated with $B$. vibrans strains. The incubation was carried out on rotary shakers at $24{ }^{\circ} \mathrm{C}$ and $150 \mathrm{rpm}$ for 25 days in dark environment.

\subsection{Extraction and Isolation}

The culture broth $(175 \mathrm{~L})$ of $B$. vibrans was filtered. The filtrate was concentrated under pressure to $10 \mathrm{~L}$ and then partition with EtOAc for four times to give a filtrate-originated EtOAc layer (170 g). Meanwhile, the mycelia were extracted by EtOH (95\%) for three times. The extraction was concentrated under pressure to remove organic solvent and then dissolve in water and partition with EtOAc for four times to give a mycelium-originated EtOAc layer $(183 \mathrm{~g})$. The total EtOAc residue was subjected to $\mathrm{CC}$ over silica gel (200-300 mesh) eluting with a gradient of petroleum ether/acetone $(100: 0 \rightarrow 0: 100)$ to give five fractions (A-E). Fraction D was separated by MPLC eluting with $\mathrm{MeOH} / \mathrm{H}_{2} \mathrm{O}(20: 80 \rightarrow 100: 0)$ to yield ten subfractions D1-D10. Subfraction D4 was subjected to HPLC to give compound 1 (1.5 mg, $\mathrm{MeCN} / \mathrm{H}_{2} \mathrm{O}, 25-45 \%, 25 \mathrm{~min}$, $\left.8 \mathrm{~mL} / \mathrm{min}, \mathrm{t}_{R}=10.6 \mathrm{~min}\right)$. Subfraction D5 was subjected to $\mathrm{HPLC}\left(\mathrm{MeCN} / \mathrm{H}_{2} \mathrm{O}, 30-50 \%, 25 \mathrm{~min}, 8 \mathrm{~mL} / \mathrm{min}\right)$ to give compounds $2\left(20.5 \mathrm{mg}, \mathrm{t}_{R}=16.5 \mathrm{~min}\right)$ and 3 (6.5 mg, $\left.\mathrm{t}_{R}=18.6 \mathrm{~min}\right)$. Subfraction D6 was separated by HPLC $\left(\mathrm{MeCN} / \mathrm{H}_{2} \mathrm{O}, 33-53 \%, 25 \mathrm{~min}, 8 \mathrm{~mL} / \mathrm{min}\right)$ to afford compounds 5 (30.3 $\left.\mathrm{mg}, \mathrm{t}_{R}=15.6 \mathrm{~min}\right)$ and $6(2.0 \mathrm{mg}$, $\mathrm{t}_{R}=16.5 \mathrm{~min}$ ). Subfraction D8 was purified by HPLC to give compound $4\left(3.0 \mathrm{mg}, \mathrm{MeCN} / \mathrm{H}_{2} \mathrm{O}, 36-56 \%, 25 \mathrm{~min}\right.$, $\left.8 \mathrm{~mL} / \mathrm{min}, \mathrm{t}_{R}=17.5 \mathrm{~min}\right)$.
Vibralactamide $A(\boldsymbol{1})$ colorless oil; $[\alpha]_{\mathrm{D}}^{25}+4.2(c$ 0.11, $\mathrm{MeOH})$; UV (MeOH) $\lambda_{\text {max }}(\log \varepsilon) 204.5$ (4.80); IR (KBr) $v_{\max } 3447,2975,2972,1637,1383,1126,1044 \mathrm{~cm}^{-1},{ }^{1} \mathrm{H}$ NMR $\left(600 \mathrm{MHz}\right.$, acetone- $d_{6}$ or DMSO- $\left.d_{6}\right)$ and ${ }^{13} \mathrm{C} \mathrm{NMR}$ ( $150 \mathrm{MHz}$, acetone- $d_{6}$ or DMSO- $d_{6}$ ) data, see Tables 1 and 2; HREIMS $\mathrm{m} / \mathrm{z} 253.1672 \mathrm{[M}^{+}$(calcd for 253.1678, $\mathrm{C}_{14} \mathrm{H}_{23} \mathrm{O}_{3} \mathrm{~N}$ ).

Vibralactone $T$ (2) colorless oil; $[\alpha]_{\mathrm{D}}^{25}-61.3$ (c 0.08 , $\mathrm{MeOH})$; UV (MeOH) $\lambda_{\max }(\log \varepsilon) 204.5$ (3.53); IR (KBr) $v_{\max } 3423,2972,2927,2863,1816,1722,1630,1379$, 1122, $977 \mathrm{~cm}^{-1} ;{ }^{1} \mathrm{H}$ NMR (600 MHz, CD $\left.{ }_{3} \mathrm{OD}\right)$ and ${ }^{13} \mathrm{C}$ NMR (150 MHz, $\left.\mathrm{CD}_{3} \mathrm{OD}\right)$ data, see Tables 1 and 2; HRESIMS $m / z, 247.0937[\mathrm{M}+\mathrm{Na}]^{+}$(calcd for 247.0941, $\left.\mathrm{C}_{12} \mathrm{H}_{16} \mathrm{O}_{4} \mathrm{Na}\right)$.

13-O-Lactyl vibralactone (3) colorless oil; $[\alpha]_{\mathrm{D}}^{25}-100.8$ (c 0.08, MeOH); UV (MeOH) $\lambda_{\max }(\log \varepsilon) 203.6$ (3.71), 217.0 (sh, 3.50); IR (KBr) $v_{\max } 3427,2971,2927,2858$, 1819, 1738, 1631, 1213, 1131, $1035 \mathrm{~cm}^{-1} ;{ }^{1} \mathrm{H}$ NMR (600 MHz, CD $\left.{ }_{3} \mathrm{OD}\right)$ and ${ }^{13} \mathrm{C}$ NMR (150 MHz, CD $\left.{ }_{3} \mathrm{OD}\right)$ data, see Tables 1 and 2; HRESIMS $\mathrm{m} / \mathrm{z} 303.1206$ $[\mathrm{M}+\mathrm{Na}]^{+}$(calcd for 303.1203, $\mathrm{C}_{15} \mathrm{H}_{20} \mathrm{O}_{5} \mathrm{Na}$ ).

10-O-Acetyl vibralactone $G$ (4) colorless oil; $[\alpha]_{\mathrm{D}}^{25}$ -10.6 (c 0.18, MeOH); UV (MeOH) $\lambda_{\max }(\log \varepsilon) 206.0$ (3.01), 257.0 (sh, 2.53); IR (KBr) $v_{\max } 3426,2973,2930$, 2858, 1746, 1632, 1381, 1245, $1044 \mathrm{~cm}^{-1} ;{ }^{1} \mathrm{H}$ NMR (600 MHz, acetone- $d_{6}$ ) and ${ }^{13} \mathrm{C}$ NMR (150 MHz, acetone$d_{6}$ ) data, see Tables 1 and 2; HRESIMS $\mathrm{m} / \mathrm{z}, 249.1100$ $[\mathrm{M}+\mathrm{Na}]^{+}$(calcd for 249.1097, $\mathrm{C}_{12} \mathrm{H}_{18} \mathrm{O}_{4} \mathrm{Na}$ ).

$(11 R, 12 R)$-Vibradiol (5) white powder; $[\alpha]_{\mathrm{D}}^{25}+9.3$ (c 0.15, MeOH); UV (MeOH) $\lambda_{\max }(\log \varepsilon) 196.5$ (4.07), 223.0 (4.51), 264.5 (3.55), 311.5 (3.42); IR (KBr) $v_{\max }$ 3449, 2977, 2925, 1637, 1384, 1262, $1126 \mathrm{~cm}^{-1}$; ${ }^{1} \mathrm{H}$ NMR (600 MHz, acetone- $d_{6}$ ) and ${ }^{13} \mathrm{C}$ NMR (150 MHz, acetone$d_{6}$ ) data, see Tables 1 and 2; HREIMS $m / z$ 234.1264 [M] ${ }^{+}$ (calcd for 234.1256, $\mathrm{C}_{14} \mathrm{H}_{18} \mathrm{O}_{3}$ ).

(11S,12R)-Vibradiol (6) white powder; $[\alpha]_{\mathrm{D}}^{25}+52.4$ (c $0.15, \mathrm{MeOH})$; UV (MeOH) $\lambda_{\max }(\log \varepsilon) 222.5$ (4.45), 264.5 (3.48), 310.5 (3.35); IR (KBr) $v_{\max } 3443,2974,2926$, 2857, 1634, 1383, 1125, $1037 \mathrm{~cm}^{-1} ;{ }^{1} \mathrm{H}$ NMR $(600 \mathrm{MHz}$, $\mathrm{CD}_{3} \mathrm{OD}$ ) and ${ }^{13} \mathrm{C}$ NMR (150 MHz, CD $\left.{ }_{3} \mathrm{OD}\right)$ data, see Tables 1 and 2; HREIMS $m / z$ 234.1255 [M] ${ }^{+}$(calcd for 234.1256, $\mathrm{C}_{14} \mathrm{H}_{18} \mathrm{O}_{3}$ ).

Single crystal $X$-ray diffraction data for vibralactone $B$ (7, MeOH) Crystal data for $\mathrm{Cu} \_7 \_0 \mathrm{~m}: \mathrm{C}_{12} \mathrm{H}_{16} \mathrm{O}_{4}$, $M=224.25, \quad a=10.0771(4) \AA, \quad b=5.8671(2) \AA$, $c=10.3263(4) \AA, \alpha=90^{\circ}, \beta=115.1150(10)^{\circ}, \gamma=90^{\circ}$, $V=552.80(4) \AA^{3}, T=100(2) \mathrm{K}$, space group $P 21, Z=2$, $\mu(\mathrm{CuK} \alpha)=0.834 \mathrm{~mm}^{-1}, 5458$ reflections measured, 1862 independent reflections $\left(R_{\text {int }}=0.0365\right)$. The final $R_{1}$ values were $0.0353(I>2 \sigma(I))$. The final $w R\left(F^{2}\right)$ values were $0.0961(I>2 \sigma(I))$. The final $R_{1}$ values were 0.0354 (all 
data). The final $w R\left(F^{2}\right)$ values were 0.0963 (all data). The goodness of fit on $F^{2}$ was 1.113. Flack parameter $=0.07(6)$. Crystallographic data for compound 7 have been deposited to the Cambridge Crystallographic Data Center (No. CCDC 1580061). These data can be obtained free of charge via http://www.ccdc.cam.ac.uk/conts/ retrieving.html.

Acknowledgements This work was financially supported by National Natural Science Foundation of China (No. 81561148013).

\section{Compliance with Ethical Standards}

Conflict of interest The authors declare no competing financial interest.

Open Access This article is distributed under the terms of the Creative Commons Attribution 4.0 International License (http://creative commons.org/licenses/by/4.0/), which permits unrestricted use, distribution, and reproduction in any medium, provided you give appropriate credit to the original author(s) and the source, provide a link to the Creative Commons license, and indicate if changes were made.

\section{References}

1. H.P. Chen, J.K. Liu, Prog. Chem. Org. Nat. Prod. 106, 1-201 (2017)

2. L. Zhang, Mini. Rev. Med. Chem. 15, 157-177 (2015)
3. H.P. Chen, Z.Z. Zhao, Z.H. Li, Z.J. Dong, K. Wei, X. Bai, L. Zhang, C.N. Wen, T. Feng, J.K. Liu, ChemistryOpen 5, 142-149 (2016)

4. H.P. Chen, Z.Z. Zhao, R.H. Yin, X. Yin, T. Feng, Z.H. Li, K. Wei, J.K. Liu, Nat. Prod. Bioprospect. 4, 271-276 (2014)

5. J.H. Ding, T. Feng, Z.H. Li, L. Li, J.K. Liu, Nat. Prod. Bioprospect. 2, 200-205 (2012)

6. M.Y. Jiang, F. Wang, X.L. Yang, L.Z. Fang, Z.J. Dong, H.J. Zhu, J.K. Liu, Chem. Pharm. Bull. 56, 1286-1288 (2008)

7. M.Y. Jiang, L. Zhang, Z.J. Dong, Z.L. Yang, Y. Leng, J.K. Liu, Chem. Pharm. Bull. 58, 113-116 (2010)

8. D.Z. Liu, F. Wang, T.G. Liao, J.G. Tang, W. Steglich, H.J. Zhu, J.K. Liu, Org. Lett. 8, 5749-5752 (2006)

9. G.Q. Wang, K. Wei, T. Feng, Z.H. Li, L. Zhang, Q.A. Wang, J.K. Liu, J. Asian Nat. Prod. Res. 14, 115-120 (2012)

10. G.Q. Wang, K. Wei, Z.H. Li, T. Feng, J.H. Ding, Q.A. Wang, J.K. Liu, J. Asian Nat. Prod. Res. 15, 950-955 (2013)

11. G.Q. Wang, K. Wei, L. Zhang, Z.H. Li, Q.A. Wang, J.K. Liu, J. Asian Nat. Prod. Res. 16, 447-452 (2014)

12. Y.L. Yang, H. Zhou, G. Du, K.N. Feng, T. Feng, X.L. Fu, J.K. Liu, Y. Zeng, Angew. Chem. Int. Ed. 55, 5463-5466 (2016)

13. P.J. Zhao, Y.L. Yang, L. Du, J.K. Liu, Y. Zeng, Angew. Chem. Int. Ed. 52, 2298-2302 (2013)

14. S.L. Zhu, P.X. Zhou, X.F. Xia, RSC Adv. 6, 63325-63330 (2016)

15. C.A. Kingsbury, C.R. Cowles, J. Org. Chem. 40, 1302-1308 (1975)

16. G.H. Schmid, Can. J. Chem. 46, 3415-3418 (1968)

17. J. Frelek, M. Geiger, W. Voelter, Curr. Org. Chem. 3, 117-146 (1999)

18. J. Frelek, N. Ikekawa, S. Takatsuto, G. Snatzke, Chirality 9, 578-582 (1997)

19. L.D. Bari, G. Pescitelli, C. Pratelli, D. Pini, P. Salvadori, J. Org. Chem. 66, 4819-4825 (2001)

20. L.D. Bari, G. Pescitelli, P. Salvadori, Chem. Eur. J. 10, 1205-1214 (2004) 